\title{
Afetividade na relação professor-aluno no ensino remoto emergencial: uma experiência de estágio
}

Jordana Gracielle de Jesus Sousa ${ }^{1}$

Gustavo Mendonça Mota²

Tatiely Pereira de Araújo Becker ${ }^{3}$

Jordana de Castro Balduino Paranahyba ${ }^{4}$

\section{RESUMO}

Objetiva-se investigar as possibilidades de construção da relação afetiva professor-aluno durante o processo de aprendizagem no contexto de ambiente virtual emergencial, decorrente da pandemia de COVID-19, a partir de um estudo de caso etnográfico e abordagem mista. Fundamenta-se em Wallon, Vigotski e Leite para pensar a afetividade presente nas decisões pedagógicas, além de outros estudos. Os resultados indicam que, apesar da falta da presença física e interação face a face, as limitações do Ensino Remoto não são impeditivos para o estabelecimento de relações afetivas positivas, embora o cenário em questão acarrete problemas e desafios educacionais que não podem ser desconsiderados.

Palavras-chave: Afetividade. Ensino Remoto. Relação professor-aluno.

\footnotetext{
${ }^{1}$ jordanagracielle18@hotmail.com - Universidade Federal de Goiás 2 gustavomendoncamota@gmail.com - Universidade Federal de Goiás 3 tatiely_pereira_araujo@ufg.br - Universidade Federal de Goiás

${ }^{4}$ jordanabalduino@ufg.br - Universidade Federal de Goiás
} 


\section{Affectivity in the teacher-student relationship in emergency remote teaching: an internship experience}

\section{ABSTRACT}

This work aims to investigate the possibilities of building affective relationships between teachers and students during the learning process in an emergency remote teaching environment, due to the Covid-19 pandemic, through an ethnographic case study and mixed approach. Wallon, Vigotski and Leite composed the theoretical framework that enabled the understanding of affectivity present in teachers' pedagogical decisions, besides more research on the same theme. Results showed that, despite the lack of physical presence and face-to-face interactions, the limitations of remote teaching are not deterrent to the foundation of positive affective relationships, even though the scenario develops educational issues and challenges that cannot be disregarded.

Keywords: Affectivity. Remote teaching. Teacher-student relationship. 


\section{INTRODUÇÃO}

O presente trabalho consiste em um estudo de caso etnográfico decorrente da experiência realizada na disciplina de Estágio Supervisionado na Formação do Professor de Psicologia I do curso de Psicologia da Universidade Federal de Goiás (UFG) durante o segundo semestre de 2020. Tendo em vista a pandemia da COVID-19 e a impossibilidade de aulas presenciais, essa disciplina foi discutida de forma a considerar um planejamento que se sustentasse nessas novas condições, colocando em destaque aquilo de que não se poderia abrir mão: a formação do professor de psicologia. Assim, a experiência de estágio aqui retratada ocorreu de forma remota com alunos do curso de Geografia da UFG na disciplina de Psicologia da Educação I, e partiu da inquietação acerca do desafio que o Ensino Remoto institui no estabelecimento da relação afetiva entre professor e aluno que favoreça as condições de aprendizagem.

A decisão de realizar um estágio on-line reverberou nos licenciandos, inicialmente, certa carga de frustração, visto que almejavam desde o começo do curso uma formação que fosse presencial, com a qual mobilizassem e fossem mobilizados por afetos, trocas e que fosse possível sentir o campo de atuação em sua totalidade. Na concepção walloniana, entende-se o sujeito como constituído na inter-relação entre ato motor, cognição e afetos; nesse sentido, a postura corporal, reações faciais, o movimento oferecem estrutura para expressão da afetividade, como um recurso fundamental para aproximar-se do outro (MAHONEY, 2004). Isso parecia limitar-se atrás de telas de computador ou celular, principalmente pela possibilidade de câmeras desligadas e por uma visualização recortada das pessoas, até mesmo embaçada a depender da qualidade da internet. Assim, a busca por essa mobilização permaneceu durante a experiência de estágio e não à toa, o tema de pesquisa aqui retratado envolve afetividade. Sendo assim, buscase discutir a afetividade na relação professor- aluno num contexto de Ensino Remoto, as dificuldades que atravessam essa relação e as ações que podem favorecer o processo de ensinoaprendizagem.

Dessa maneira, este trabalho é organizado da seguinte forma: primeiro, é exposta a fundamentação teórica que sustenta esta análise, subdividida em Afetividade na relação pedagógica, subseção que, à luz de Wallon, Vigotski, Sérgio Leite e outros autores, lança mão da construção teórica acerca da afetividade constituinte do sujeito e também da mediação pedagógica, de suma importância para uma boa relação com o objeto do conhecimento; e Pandemia e Ensino Remoto, que descreve o contexto excepcional no qual ocorreu esta experiência, assim como os desafios impostos por esse momento. Depois disso, é apresentada a metodologia, subdividida em procedimentos e caracterização do campo de estágio, promovendo uma aproximação maior com o campo e de como foi realizada a pesquisa. Em seguida, são abordados resultados e discussões e, por fim, as considerações finais. 


\section{FUNDAMENTAÇÃO TEÓRICA E METODOLOGIA}

\subsection{Afetividade na relação pedagógica}

A desvalorização histórica da afetividade no âmbito escolar enquanto objeto de estudo científico e como fator a ser considerado para a prática docente dificulta ainda hoje as reflexões acerca da relação professor e aluno, tendo em vista o processo de ensino-aprendizagem, que não se restringe meramente à dimensão cognitiva. Nesse sentido, é importante pensar em uma concepção de sujeito histórico e integral. Segundo a teoria psicogenética de Wallon (2007), o desenvolvimento humano engloba os campos funcionais afetivo, motor e cognitivo e sua relação com o meio físico, social e cultural. Partindo disso, como descreve Galvão (2003), Wallon propõe uma síntese dialética entre cognição e afeto a fim de superar a dicotomia entre razão e emoção, porque são, na verdade, aspectos indissociáveis à formação humana, inter-relacionados de forma mútua e recíproca, um impactando na evolução do outro.

A afetividade para Wallon refere-se à disposição do ser humano de ser afetado pelo mundo externo ou interno, por sensações ligadas a tonalidades agradáveis ou desagradáveis (MAHONEY; ALMEIDA, 2005), tendo em vista relações dialéticas entre o orgânico e o social. Assim, "além de envolver um componente orgânico, corporal, motor e plástico [...], apresenta também um componente cognitivo, representacional [...]" (DÉR, 2004, apud LEITE, 2012, p. 360), no qual a sociedade, a cultura e o outro são determinantes no curso de seu desenvolvimento.

Outro autor que dá base para a concepção de sujeito que sustenta esse trabalho é L. S. Vigotski (1998). O referido autor defende que o indivíduo nasce como ser biológico e por meio das interações e da inserção na cultura, constitui-se em um ser histórico e cultural, sob o enfoque da mediação. Esse é um conceito caro à sua teoria: a relação do sujeito com o mundo não é direta, é mediada pelo outro, que possui papel fundamental no processo de aprendizagem e desenvolvimento. Nessa perspectiva, pode-se pensar que a construção do conhecimento é uma atividade que "envolve três elementos, não apenas dois: o sujeito que conhece, a coisa a conhecer e o elemento mediador que torna possível o conhecimento" (PINO, 1997, apud TASSONI, 2000, p. 02). Essa noção é fundamental para o entendimento da mediação no contexto pedagógico, sendo o professor um grande responsável dessa ação.

À medida que se assume que o processo de aprendizagem é social e implica o outro e a cultura, evidencia-se a qualidade das interações e mediações em que estão envolvidos não só aspectos cognitivos, mas principalmente afetivos: o ensinar e o aprender se pautam a partir de relações afetivas com o outro e também assim, o objeto do conhecimento é marcado por significados e sentidos por conta dessa vivência com as pessoas e o mundo (TASSONI, 2000). Assim, baseado em grandes teóricos como Henri Wallon e Vigotski, Sérgio Leite (2012) compreende dois pontos principais: que a relação entre sujeito e objeto do conhecimento é mediada e, além disso, é atravessada pelos âmbitos cognitivo e afetivo, desenvolvendo um modelo teórico importante para a atuação docente. Apesar de não ser o único agente, o professor em sala de aula é o principal mediador entre o aluno e o conteúdo escolar e, portanto, considerar que a afetividade perpassa e constitui as práticas pedagógicas é também reconhecer que o professor deve estar atento aos impactos afetivos dessa mediação, que pode tanto aproximar o 
aluno do conteúdo - relação afetiva positiva - quanto afastá-lo - relação afetiva negativa -, segundo o autor.

É necessário pontuar que a mediação pedagógica não é um conceito abstrato ou metafórico, pelo contrário, é concreto e vivenciado em diversas instâncias do contexto escolar. Leite (2012) defende que em todas as decisões planejadas e desenvolvidas pelo professor há repercussões afetivas. $O$ autor identifica e destaca cinco dessas decisões, sendo elas: (1) a escolha dos objetivos de ensino; (2) a decisão sobre o início do processo de ensino; (3) a organização dos conteúdos de ensino; (4) a escolha dos procedimentos e atividades de ensino; (5) a escolha dos procedimentos de avaliação do ensino.

A escolha dos objetivos de ensino (1) está relacionada às concepções, valores e crenças dos professores ou instituição, ou seja, faz parte tanto do projeto pedagógico da escola quanto da delimitação de objetivos específicos das unidades curriculares. 0 caráter afetivo dessa decisão está na relevância de tais objetivos para sua vida, seu futuro e para a sociedade. Sendo assim, a formação de vínculos afetivos positivos apoia-se na definição de objetivos significativos para os alunos, que possibilitem não somente o acúmulo de conhecimentos, mas também uma formação crítica e transformadora.

A decisão sobre o início do processo de ensino (2) também é importante para que os alunos possam estabelecer uma relação afetiva positiva com o objeto de conhecimento, po is "iniciar o ensino a partir do que o aluno já sabe sobre os conteúdos envolvidos aumenta as possibilidades de sucesso do processo de aprendizagem do próprio aluno" (LEITE, 2012, p. 363). Por isso, o autor defende uma avaliação diagnóstica acerca dos conteúdos mais elementares como condição prévia para o início do processo de ensino.

A organização dos conteúdos de ensino (3), de maneira sequencial e lógica, respeitando a estruturação própria de cada área, favorece a aprendizagem dos alunos e sua relação com o objeto de conhecimento, assim como a desorganização ou aleatoriedade com que os conteúdos venham a ser trabalhados pode promover efeitos contrários.

A escolha dos procedimentos e atividades de ensino (4) compreende as estratégias elaboradas pelo professor, com base nos objetivos propostos, de como serão realizadas as ações em sala de aula e, consequentemente, sob quais circunstâncias dar-se-ão as relações naquele ambiente. Segundo ele:

Neste sentido, é inegável a implicação da dimensão afetiva em cada atividade planejada e desenvolvida. Atividades bem escolhidas e adequadamente desenvolvidas, sem dúvida, aumentam as chances do aprendizado com sucesso por parte do aluno e a consequente relação afetiva entre o aluno e os conteúdos envolvidos (LEITE, 2012, p. 364).

Por fim, a escolha dos procedimentos de avaliação do ensino (5) não é menos importante, seja no sentido de aproximar ou distanciar afetivamente o aluno do conteúdo. Sérgio Leite defende a avaliação diagnóstica (LUCKESI, 1984, apud LEITE, 2012, p. 365) como meio de obter informações a respeito do que foi apropriado pelo aluno e também traçar estratégias para alcançar aquilo que não foi, ou seja, um modelo de avaliação que favoreça o processo de ensinoaprendizagem. 
Vale retomar que a afetividade é um conceito amplo, fundamental para o desenvolvimento humano e que envolve manifestações de origem biológica e também psicológica, tensionando a relação dialética entre essas dimensões. Ela tem caráter comunicativo e expressivo e consequentemente, de aproximação com o outro: a afetividade sinaliza como o ser humano é afetado pelo mundo externo e interno, biológico e social, e tem apoio no ato motor e no cognitivo (MAHONEY, 2004). Junto a essa ideia, considera-se que a afetividade está presente no contexto educacional e especificamente, na mediação pedagógica, pois toda aprendizagem tem uma base afetiva, já que ocorre por interações sociais entrelaçadas por afetos. Assumir o professor como importante mediador do conhecimento é reconhecer que, para que o conteúdo ganhe sentido e significado, como defende Tassoni (2000), pressupõe-se relações afetivas, que são reveladas nos elos interpessoais entre professor e aluno, nas posturas do professor, na criação de um clima acolhedor e favorável para aprendizagem e na tomada de decisões pedagógicas que considerem o aluno e sua realidade, visando a construção efetiva do conhecimento.

Por fim, ressalta-se a relevância dada à qualidade da mediação do professor: é essa qualidade um dos principais determinantes para uma aprendizagem significativa. Sendo assim, é inviável planejar as condições de ensino sem levar em consideração uma concepção de sujeito completo, a importância da mediação e a forma com que a afetividade perpassa as condições de aprendizagem para uma boa relação entre sujeito e objeto a ser conhecido.

\subsection{Pandemia e Ensino Remoto}

No dia 11 de março de 2020, a Organização Mundial da Saúde (OMS) declarou estado de pandemia pela COVID-19 (BBC NEWS BRASIL, 2020), e, com o objetivo de evitar a disseminação do vírus, diversas medidas foram tomadas a nível nacional. A Secretaria de Estado de Saúde (SES) de Goiás determinou a paralisação das aulas presenciais em todos os níveis educacionais e públicos pela Nota Técnica n. 1/2020 (GOIÁS, 2020), o que também ocorreu em outros Estados da federação.

Nesse viés, o Ministério da Educação (MEC) no dia 17 de março de 2020, por meio da Portaria $n^{\circ}$. 343/MEC (BRASIL, 2020a), orientou a substituição de aulas presenciais por aulas em meios digitais. Outras Portarias foram divulgadas, e, no dia 16 de junho de 2020, a Portaria n ${ }^{\circ}$ 544/MEC (BRASIL, 2020b) resolveu que a substituição de práticas profissionais de estágios deveria obedecer às Diretrizes Nacionais Curriculares aprovadas pelo Conselho Nacional de Educação (CNE), permitindo, até o dia 31 de dezembro de 2020, que as disciplinas presenciais fossem substituídas, em caráter excepcional, por atividades letivas que dispusessem de recursos educacionais digitais, tecnologias de informação e comunicação. Determinou, ainda, que as instituições de ensino fossem responsáveis por definir os componentes curriculares a serem substituídos, bem como oferecer recursos aos alunos que permitissem o acompanhamento das atividades letivas ofertadas.

O Ensino Remoto Emergencial (ERE) foi uma resposta de várias instituições escolares para adaptar o Ensino Presencial interrompido pela pandemia, porém tal modalidade diferencia-se da Educação a Distância (EaD) em vários aspectos (JOYE; MOREIRA; ROCHA, 2020). A Educação a

Distância é uma modalidade de ensino prevista na legislação brasileira desde 1996 (LDB) e reafirmada no Decreto Lei $n^{\circ}$ 9.057/2017: 
Art. $1^{\circ}$ Para os fins deste Decreto, considera-se educação a distância a modalidade educacional na qual a mediação didático-pedagógica nos processos de ensino e aprendizagem ocorra com a utilização de meios e tecnologias [digitais] de informação e comunicação [TDICS], com pessoal qualificado, com políticas de acesso, com acompanhamento e avaliação compatíveis, entre outros, e desenvolva atividades educativas por estudantes e profissionais da educação que estejam em lugares e tempos diversos (BRASIL, 2017).

O ERE, por outro lado, é marcado por seu caráter circunstancial, por atividades totalmente virtuais adotadas durante o período de distanciamento social e, portanto, não configura um novo modelo educacional. A semelhança com o formato à distância, nesse sentido, dá-se pela mediação de tecnologias digitais.

A UFG não aderiu ao Ensino Remoto tão logo ocorreu a suspensão das aulas presenciais: continuar sem o mínimo de planejamento seria ignorar e ferir toda a diversidade de realidades que compõem a comunidade acadêmica, como estudantes que estão em situação de vulnerabilidade, incluindo indígenas, quilombolas e estudantes com alguma deficiência. Sendo assim, uma série de reuniões ocorreu na intenção de pensar alternativas para esse contexto, de forma a tentar preservar a capacidade formativa da instituição. No dia 03 de julho de 2020, o Conselho Universitário da UFG aprovou a retomada do semestre com atividades remotas. Em um movimento conjunto, Reitoria, em parceria com várias comissões criadas para abordar a situação vigente estudaram, discutiram possibilidades e executaram ações para diminuir minimamente as disparidades sociais entre os estudantes nesse retorno.

Dentre essas ações, destaca-se a Portaria SEl n 10, do dia 10 de junho de 2020 (UFG, 2020a), que dispõe sobre o Plano Emergencial de Conectividade da Universidade Federal de Goiás e que consistiu em repassar mensalmente a quantia de $\mathrm{R} \$ 50,00$ reais ao estudante incluído, a fim de contribuir para o acesso dos estudantes de baixa renda à internet, tornando possível o acompanhamento das atividades de forma remota durante a pandemia a partir das Tecnologias Digitais de Informação e Comunicação (TDIC).

Aliado a isso, foi concretizada a Campanha UFG ID (SÁ et al., 2020), que teve como objetivo mobilizar a sociedade para a doação de equipamentos eletrônicos, como computadores e tablets, além de doações financeiras para a compra desses equipamentos, a fim de atender à necessidade educacional de muitos estudantes. Ainda, foi elaborada pelo Conselho Universitário (Consuni) a Resolução Nº. 0027/2020 (UFG, 2020b), que regulamenta o empréstimo emergencial de equipamentos de informática aos estudantes de Educação Básica, graduação e pós-graduação stricto sensu da UFG.

A retomada do semestre letivo de 2020.1 ocorreu no dia 31 de agosto de 2020, com uma série de recomendações institucionais, tendo em vista uma perspectiva de redução de impactos decorrentes desse modelo emergencial, como maior flexibilidade de prazos e volume de atividades, além da divisão da carga horária em momentos síncronos e assíncronos. Ainda assim, esse retorno foi e se mantém marcado por controvérsias tangentes à exclusão digital e também à saúde mental de educadores e educandos. 
Diante desse Ensino Remoto e da importância da afetividade no processo ensinoaprendizagem, surge a questão que norteia esse texto: é possível a construção de uma relação afetiva positiva entre professor e aluno num contexto pandêmico marcado por incalculáveis impactos não só no campo educacional, mas também social, econômico e sanitário?

\subsection{Procedimentos}

De acordo com Lima e Pimenta (2006), a finalidade do estágio é fazer com que o aluno se depare com a realidade em que irá atuar e adote, diante dela, uma postura reflexiva e crítica. Por isso, os autores defendem que o estágio seja uma atividade ao mesmo tempo prática, por meio do contato com o campo de atuação, e teórica, de modo que o campo torne-se também objeto de pesquisa.

Essa é uma estratégia que pretende, além de romper com uma visão dicotômica entre teoria e prática, colocar o estagiário numa posição investigativa, de produção de conhecimento, e não simplesmente de aplicação de teorias e técnicas. Trata-se, portanto, de uma concepção que rompe com a ideia de que o estágio seria apenas a parte prática do curso.

Partindo dessa concepção de estágio, no que se refere ao aspecto metodológico, este trabalho fundamenta-se no estudo de caso do tipo etnográfico e de abordagem mista. Para isso, foram utilizados como instrumentos a observação-participante, produção de diário de campo, aplicação de questionário e análise dos documentos do campo, como Projeto Pedagógico do Curso (PPC) e resoluções acerca da política presente na formação de professores da UFG.

De acordo com Creswell (2007), a conciliação entre diferentes métodos de pesquisa teria surgido ao final da década de 1950 em um estudo de Campbell e Fiske sobre a validade das características psicológicas. Desde então, essa prática passou a ser adotada por outros pesquisadores, grande parte pertencente às ciências humanas e sociais, mas não somente, dando origem a uma variedade de procedimentos e tornando-se cada vez mais comum.

A abordagem mista rompe com a ideia de que as abordagens qualitativa e quantitativa são incompatíveis e reúne elementos de ambas, a fim de permitir uma leitura mais ampla do problema pesquisado (CRESWELL, 2007). Trata-se, portanto, de um método que coleta e analisa informações numéricas e textuais, sendo indicado, principalmente, nos casos em que a análise do fenômeno exige mais de uma fonte de dados. Os resultados qualitativos auxiliam na compreensão dos dados quantitativos quando a literatura é escassa e há necessidade de uma exploração qualitativa antes de uma análise quantitativa ou quando as abordagens, isoladamente, são consideradas insuficientes (CRESWELL; CLARK, 2013 apud SANTOS et al., 2017). Essa última indicação justifica a escolha metodológica do presente artigo.

Para chegar próximo dos objetivos propostos, tanto a coleta de dados quantitativos quanto qualitativos foi considerada imprescindivel. Saber a avaliação que os alunos fizeram, a partir de parâmetros previamente definidos, das atitudes dos professores ao final da disciplina possibilita uma visão geral sobre a experiência da turma. Por outro lado, compreender a relação afetiva dos alunos com os objetos de ensino exige também informações mais particulares sobre suas vivências ao longo das aulas e os motivos que eles atribuem à construção de uma relação positiva ou não com a disciplina. 
Nesse sentido, a coleta de dados foi realizada simultaneamente por meio da aplicação de um questionário on-line contendo 19 questões - abertas, semiabertas e fechadas. Algumas perguntas foram formuladas com a intenção de levantar características da turma, como idade, se já haviam tido alguma experiência como docente, se já tinham concluído alguma outra graduação. Outras questões focaram nas condições de acessibilidade dos alunos durante o período de aulas remotas, como disponibilidade de equipamentos eletrônicos para acompanhar as aulas e atividades, se tais equipamentos eram de uso pessoal ou compartilhado com outras pessoas, qualidade da internet. Por fim, foram elaboradas, com base nas decisões pedagógicas abordadas por Sérgio Leite (2012), indagações acerca da relação afetiva dos alunos com a disciplina.

Os resultados obtidos foram analisados de forma integrada, de modo a identificar ou não convergências entre ambos. Quando identificadas, tais convergências fortalecem a hipótese apresentada. Esse procedimento de metodologia mista é denominado por Creswell (2007) de estratégia de triangulação concomitante.

Segundo Viegas (2007), o estudo de caso etnográfico vem ocupando lugar crescente nas pesquisas qualitativas em educação e consiste em unir características tanto do estudo de caso quanto da etnografia. 0 estudo de caso é o estudo exaustivo de uma unidade, um caso particular, tentando tensionar constantemente seu dinamismo próprio e singular com a complexidade da realidade na qual está situado. Por sua vez, a etnografia dispõe-se, por exemplo, em estabelecer relações, mapear campos, manter um diário, com a intenção última de uma descrição densa do campo escolhido (GEERTZ, 1989 apud VIÉGAS, 2007). Essa junção permite que se tenha um olhar mais próximo do campo de pesquisa, para tentar compreender as relações e as interações que formam seu dia a dia, tendo em vista um recorte de análise, além de marcar um contato direto entre pesquisador e situação pesquisada, da qual ele também faz parte.

Assim, vale destacar que no estudo de caso etnográfico o pesquisador não só observa, mas interpreta a realidade com a qual está em contato, considera os diferentes sujeitos que a compõem e como eles vivenciam essas experiências, não com o intuito de buscar uma realidade única, mas a pluralidade de vozes, incluindo a do pesquisador, considerando evidenciar possíveis contradições (VIÉGAS, 2007).

Diante do exposto, o presente trabalho propõe uma análise crítica a partir do estudo de um caso particular de experiência de estágio, evidenciando a realidade em que isso ocorreu: um período pandêmico, em uma modalidade de ensino emergencial.

Assim sendo, também se destaca que este relato parte da vivência de dois estagiários sob a orientação e supervisão das duas professoras da disciplina de estágio. Tal apoio deu maior amplitude e nitidez aos olhares inexperientes de quem começara a conhecer o campo de atuação. Não obstante, buscou-se transformar o desafio de sintetizar duas visões distintas em uma vantagem e não um obstáculo, no sentido de tensionar duas perspectivas, a fim de retratar o dinamismo da situação de maneira mais próxima do seu acontecer natural e pensar objetivos e incômodos em comum para a produção deste estudo. 


\subsubsection{Caracterização do campo de estágio}

Devido à pandemia da COVID-19, o estágio de Licenciatura em Psicologia, que antes era realizado em um Centro Municipal de Educação Infantil (CMEI) e envolvia a elaboração de um curso de formação para auxiliares educativas, precisou sofrer modificações e adaptações; ocorreu de forma remota em outro campo: o Ensino Superior, nas disciplinas de Psicologia da Educação I e II dos cursos de licenciatura da UFG. Os cursos de licenciatura desta Instituição de Ensino Superior (IES) visam uma formação centrada na práxis, que envolve reflexão e investigação da realidade escolar e consequentes relações com saberes específicos, científicos, pedagógicos e culturais, colocando em evidência a construção de uma sociedade humana e transformadora, de forma a considerar a indissociabilidade entre teoria e prática. Assim, o projeto institucional da universidade compreende que, para que haja uma formação que permita aos futuros professores uma compreensão e consequente intervenção na realidade social em que a escola se insere, é necessário que os conhecimentos adquiridos ao longo do curso se pautem de maneira a promover reflexões, fomentar problematizações e o constante planejamento do fazer pedagógico do licenciado (UFG, 2017).

Conhecimentos das áreas específicas, interdisciplinares e do campo educacional constituem conhecimentos e saberes definidos na UFG como fundamentais à formação de professores. De forma geral, os conhecimentos do campo educacional tratam o contexto social, político e econômico da educação, assim como discussões mais profundas acerca dela; conhecimentos referentes a processos de desenvolvimento e aprendizagem dos educandos; discussões que abordam gênero, sexualidade, diversidade étnico-racial, especificidade de alunos com deficiência e direitos humanos; políticas educacionais, gestão, didática e conhecimentos sobre currículo e avaliação (UFG, 2017). Tais saberes e conhecimentos devem ser contemplados nas ementas dos componentes curriculares obrigatórios dos cursos de licenciatura, cujas formações ocorrem em parceria com a Faculdade de Educação, unidade acadêmica a qual estão vinculados os cursos de pedagogia e psicologia. Esses componentes são: Psicologia da Educação I - 64 h; Psicologia da Educação II - 64 h; Políticas Educacionais no Brasil - 64 h; Fundamentos Filosóficos e Sócio-Históricos da Educação - 64 h.

A experiência de estágio da qual decorreu este trabalho deu-se no curso de Licenciatura em Geografia, por meio da disciplina de Psicologia da Educação I, ofertada no terceiro período da graduação. O curso de Geografia foi criado em 1965 juntamente com o curso de História, ano em que foi aprovado o Regimento da Faculdade de Filosofia, Ciências e Letras. Atualmente é vinculado ao Instituto de Estudos Socioambientais da mesma instituição; possui duração mínima de 4 anos - 8 semestres - e, desde 2011, a escolha entre bacharelado e licenciatura ocorre já no processo seletivo para o ingresso (UFG, 2015).

A organização e o conteúdo do currículo do curso de Licenciatura em Geografia enfatiza o raciocínio e a visão crítica do estudante, visando os seguintes objetivos:

[...] formar profissionais articulados com os problemas atuais da sociedade e possibilitar que os mesmos possam agir, social e profissionalmente, alicerçados em uma boa qualidade teórica para o seu desempenho profissional; desenvolver no licenciando a construção de conhecimentos e conviç̧ões concernentes à ciência geográfica, aos processos sociais, psicológicos e 
pedagógicos, para atuar de forma crítica e reflexiva na Educação Básica, assim como para prosseguir estudos em cursos de pós-graduação em nível de especialização, mestrado e/ou doutorado (PROGRAD, 2020).

Partindo para o campo mais específico de estágio, a ementa da disciplina de Psicologia da Educação I envolve o estudo introdutório de psicologia, seus aspectos históricos e epistemológicos; a relação entre psicologia e educação e o estudo da abordagem comportamental e psicanalítica visando a compreensão do desenvolvimento cognitivo, afetivo, social e psicomotor e suas contribuições e implicações para o processo de ensino-aprendizagem (UFG, 2015). A carga horária da disciplina foi dividida em momentos síncronos, nos quais houve semanalmente encontros virtuais por meio da plataforma Google Meet, e em momentos assíncronos. Nos momentos síncronos, ocorreram aulas expositivas, com utilização de slides e vídeos, momentos de interação com os alunos e discussão dos conteúdos abordados. Em contrapartida, os momentos assíncronos ficaram reservados para atividades como leitura e produção de textos e também para os filmes e vídeos indicados.

Composta por 28 integrantes, com idade variando entre 19 a 42 anos, a turma continha alunos com diferentes realidades, alguns trabalhavam, algumas eram mães, havia alunos indígenas, quilombolas, alunos que estavam na segunda ou até na terceira graduação e cerca de um terço atuavam ou já tinham atuado como docentes. Ao longo do período, alguns estudantes relataram dificuldades em acompanhar ou participar das aulas por problemas em equipamentos como fones de ouvido e microfone, mas principalmente por uma conexão de internet ruim. Apesar dos impasses, boa parte da turma participou ativamente da maioria das aulas, com dúvidas, debates e reflexões.

Inicialmente, a disciplina de Psicologia da Educação I começou a ser ministrada por outra professora. Foram apenas duas aulas até a interrupção das atividades presenciais, e quando as aulas voltaram, os estagiários e a professora supervisora assumiram a disciplina. Nos dois primeiros encontros com a turma, a antiga professora intermediou o contato com os alunos e também apresentou o plano de ensino, por ela elaborado, deixando os novos encarregados à vontade para repensar e reelaborar pontos que fossem considerados passíveis de alterações.

\section{RESULTADOS E DISCUSSÕES}

Para analisar os dados obtidos através da aplicação de questionário on-line, toma-se como base as cinco decisões pedagógicas e outras atitudes do professor apresentadas por Sérgio Leite (2012) que interferem, inevitavelmente, na relação afetiva professor-aluno, para pensar os desafios impostos à educação pelo Ensino Remoto.

A escolha dos objetivos de ensino refere-se à relevância dos objetivos para a vida do aluno, seja daqueles elaborados para uma unidade curricular específica ou, de forma mais abrangente, dos que compõem o projeto pedagógico da instituição. Diante disso, surgem algumas questões que estão em pauta desde a interrupção das aulas pela pandemia e que ainda permanecem desafiadoras após tantos meses: será possível alcançar os objetivos estabelecidos no projeto pedagógico por meio de um Ensino Remoto Emergencial? Se sim, como fazê-lo, já que se trata de 
uma atividade que já nasce excludente quanto às condições de acesso de muitos estudantes? Ignorar ou atropelar reflexões como essas contribui para uma escola divorciada da realidade.

De acordo com os dados obtidos, $18,2 \%$ dos alunos responderam que tiveram que recorrer ao Plano de Conectividade Emergencial ou a outros programas de assistência estudantil da UFG. Além disso, 22,7\% cancelaram alguma disciplina, após o retorno remoto das atividades acadêmicas, sendo que os principais motivos relatados foram: dificuldades de acesso à internet e outros recursos (66,7\%); as atividades, trabalhos e provas pareciam muito difíceis $(66,7 \%)$; adaptações de rotina por conta da pandemia, seja por cuidados com familiares, trabalho, atividades domésticas, etc. (50\%); saúde mental afetada (33,3\%). Outro aspecto investigado foi com relação à disciplina de Psicologia da Educação I, em que aproximadamente um terço da turma (31,8\%) pensou em abandonar a disciplina em algum momento. Entre os principais motivos alegados estão novamente: adaptações de rotina por conta da pandemia, seja por cuidados com familiares, trabalho, atividades domésticas, etc. (87,5\%); dificuldades de acesso à internet e outros recursos (37,5\%); saúde mental afetada (25\%); as atividades, trabalhos e provas pareciam muito difíceis (25\%). Esses são alguns dos dados que levam a pensar o quanto a pandemia impactou diferentemente a realidade dos alunos. Não obstante, o Plano de Conectividade Emergencial mostrou-se fundamental para que alguns alunos pudessem continuar acompanhando as aulas remotamente.

Apesar das mudanças de realidade e do cenário desigual quanto à acessibilidade, todos os alunos consideraram relevantes, para a vida pessoal e profissional, os conteúdos da disciplina, sendo que $36,4 \%$ classificaram os conteúdos como "relevantes" e 63,6\%, como "muito relevantes". Vale aqui citar uma das respostas obtidas quando foi perguntado quais razões os levaram a pensar em cancelar a disciplina de Psicologia da Educação I:

Quando pensei no curso de licenciatura eu quis aproveitar ao máximo todas as oportunidades, e fiquei extremamente perdido quando não fazia sentido pra mim ter aulas de educação fora da sala de aula, são matérias muito importantes pra sofrer implicações de problemas virtuais, mas segui firme, foi apenas um peso individual, não relacionado ao conteúdo ou professoras (Estudante de Geografia, resposta retirada de questionário aplicado on-line, 2020).

Esse relato dá sinais da complexidade que é analisar os aspectos afetivos num contexto de tantas transformações, com tantas variáveis envolvidas. Apesar de se ter conseguido auxiliar os alunos a compreenderem a relevância dos conteúdos para suas vidas, fica evidente que esse foi um processo árduo, não só da parte dos estagiários, mas também da parte dos alunos.

A fim de avaliar a decisão sobre o início do processo de ensino, os estudantes foram questionados se os professores da disciplina se preocuparam em saber o nível de domínio dos alunos acerca dos conteúdos abordados e se tomaram os conhecimentos prévios como ponto de partida para facilitar a aprendizagem. Nesse ponto, 78,8\% responderam que sim; $15,1 \%$ disseram que os professores procuraram saber o nível de domínio que os alunos tinham dos conteúdos, mas não alteraram a forma de abordar os assuntos. Os outros $6 \%$ marcaram que os conhecimentos prévios dos alunos não foram considerados.

Para que se reduzam as chances de fracasso e de uma relação afetiva negativa do aluno para com o objeto de ensino, Sérgio Leite (2012) defende que o ensino deve iniciar-se após uma 
breve avaliação diagnóstica. Apesar de uma avaliação diagnóstica propriamente dita não ter sido estruturada, a professora e os estagiários, no decorrer das aulas, incentivaram os alunos a compartilharem seus conhecimentos sobre os objetos de ensino, pelo chat ou por voz. Todavia, essa estratégia não atingiu a todos os alunos, já que muitos não participavam das aulas com frequência.

Como já foi descrito, a professora supervisora e os estagiários assumiram a disciplina em andamento, com um plano de ensino previamente elaborado pela docente que iniciou as primeiras aulas, ainda no período presencial. Por conta disso, e principalmente pela liberdade e confiança dadas pela supervisora, foi possível uma participação mais ativa dos estagiários na reelaboração do plano de ensino, experiência essa que foi extremamente formativa. Essa reconstrução do plano ocorreu por conta de divergências com alguns pontos, em especial, com a organização dos conteúdos da disciplina. Todavia, essa reestruturação teve de acontecer ao longo das aulas e alguns aspectos do plano anterior tiveram que ser mantidos, pois já havia atividades em andamento.

Apesar disso, 77,3\% afirmaram que a apresentação dos conteúdos seguiu uma sequência lógica e coerente, facilitando a aprendizagem, enquanto 9,1\% avaliaram a organização dos conteúdos como pouco coerente e nenhum aluno considerou que os conteúdos foram organizados de maneira confusa e de difícil compreensão. De certa forma, a reorganização concomitante ao andamento das aulas, motivo de grande preocupação da professora e dos estagiários durante o período letivo, não teve efeitos tão prejudiciais.

Quanto à escolha dos procedimentos e atividades de ensino num contexto remoto, foram adotadas diferentes estratégias, com a intenção de tornar as aulas mais dinâmicas, dentre as quais: aulas expositivas, apresentação de slides, vídeos, filmes e momentos de diálogo. Quando questionados a respeito dessa decisão, para 90,9\% dos alunos as estratégias adotadas facilitaram a aprendizagem dos conteúdos; no entanto, uma das respostas obtidas nessa mesma questão, que permitia respostas fechadas e abertas, retrata outra realidade: "em decorrência da peculiaridade do EaD todo o meu desenvolvimento de ensino foi prejudicado então é difícil fazer um bom juízo sendo que eu não sei dissociar o que é dessa disciplina em si e o que é decorrente do EaD" (Estudante de Geografia, resposta retirada de questionário aplicado on-line, 2020). Embora haja uma série de ferramentas e plataformas virtuais com diferentes recursos e possibilidades para o ensino, o desconhecimento e a falta de formação não só de professores, mas também de alunos para lidar com tais recursos podem ter um efeito oposto ao desejado, dificultando o estabelecimento de vínculos afetivos positivos entre alunos e objeto de conhecimento. Aliás, não se trata simplesmente de dominar uma gama de ferramentas virtuais, mas, também, de saber que tipo de relações é possível desenvolver por meio delas, para o que são eficazes e para o que não são. Como alerta Leite (2012):

Por outro lado, a escolha dos procedimentos e atividades de ensino apresenta inúmeros desafios que podem transformar tais escolhas em verdadeiras condições de fracasso para o aluno: é o caso, por exemplo, da escolha inadequada de uma atividade, tendo em vista o objetivo proposto (p. 364). 
Além disso, aqui também se evidenciam, por meio da resposta obtida, as contradições que permeiam o campo, pela dificuldade de discernir o que é de fato do Ensino Remoto e o que é da disciplina, porque, em algum momento, os dois se imbricam.

Diante de um contexto educacional, sanitário e social sem precedentes e sem o devido preparo de docentes e discentes para com a nova realidade educacional, em vários momentos as aulas tornaram-se uma espécie de laboratório experimental, quando diferentes procedimentos foram testados por tentativa e erro. Nesse sentido, as supervisões e as aulas da disciplina de estágio foram muito importantes, já que ouvindo também as experiências dos outros estagiários foi possível pensar em novas possibilidades e evitar alguns erros.

No caso da escolha dos procedimentos de avaliação do ensino, foi grande a dificuldade em encontrar um equilíbrio entre a necessidade de um processo contínuo de avaliação, que fornecesse ao professor informações acerca do nível de apropriação do aluno sobre os conteúdos e condições de repensar estratégias de ensino, e uma quantidade de atividades que não sobrecarregasse os estudantes. Diferentemente do Ensino Presencial, na atividade remota, o professor tem poucas condições de avaliar a apreensão dos alunos durante a exposição de um conteúdo. Câmeras desligadas e participações apenas por voz ou por chat impedem sinais preciosos como expressões faciais, postura corporal e até mesmo a verificação de presença em aula. Por isso, os procedimentos avaliativos tornam-se ainda mais importantes. Houve, porém, momentos em que os alunos queixaram-se da quantidade de atividades, não somente nesta disciplina, mas de modo geral, o que resultou, por parte da professora supervisora, na flexibilização dos prazos de entrega de atividades avaliativas.

Quando questionados especificamente a respeito de suas experiências ao longo do Ensino Remoto, afirmaram que têm tido mais dificuldade em se concentrar nas aulas $77,3 \%$ dos alunos; $50 \%$ relataram que têm sido mais difícil aprender e $63.6 \%$ disseram que atividades simples, em frente ao celular ou computador, tornaram-se mais cansativas. É fundamental, portanto, que a avaliação seja utilizada em favor do aluno (LEITE, 2012), e nesse caso, considere o contexto excepcional em que se deu o processo de ensino-aprendizagem.

É válido mencionar que para grande maioria, a substituição da professora que iniciou o semestre por outra professora e seus estagiários não diminuiu as expectativas em relação à disciplina, como apontava a preocupação inicial após as primeiras aulas. Alguns alunos de fato afirmaram ter sentido essa troca, mas houve quantidade significativa de respostas indicando que as expectativas foram atingidas e até superadas. Destaca-se a seguinte:

De primeira havia ficado meio perdido, pois apesar de ainda não ter tido aulas suficientes com a primeira professora, já havia estabelecido um conceito, e estabelecer esse novo contato por meio virtual foi diferente, inesperado, mas sem expectativas ruins, apenas no sentido de ser difícil estabelecer uma conexão com os docentes. $E$ acabei sendo surpreendido, pois gostei muito da professora e dos estagiários [sic] (Estudante de Geografia, resposta retirada de questionário aplicado on-line, 2020).

Nota-se que o receio que impulsionou esta pesquisa foi também apontado por esse aluno e por outros ao longo das demais respostas, o que indica que não é uma preocupação de mão 
única, embora seja papel do professor criar condições para que haja um ambiente afetivo saudável para o aprendizado.

Com a intenção de analisar questões importantes na relação professor-aluno, foi perguntado quais posturas e atitudes dos professores estavam presentes na disciplina de Psicologia da Educação I. Dentre as respostas, o resultado foi: abertura para o diálogo (77,3\%), acolhimento das participações, dúvidas, comentários e reflexões (100\%), sensação de proximidade com o professor (54,5\%) e flexibilidade (45,5\%). É interessante notar que houve a criação de um clima que deixasse os alunos à vontade para perguntar e participar, condição fundamental para a construção do conhecimento. Segundo Vigotski (1998), é na interação com o outro que o sujeito se forma e uma relação afetiva positiva na triangulação do saber pode contribuir para uma aprendizagem significativa. Outro ponto a se pensar é a sensação de proximidade com o professor. Mesmo com a sala de aula reconfigurada em sua complexidade para além do espaço físico, pouco mais da metade dos alunos pôde identificar essa sensação, o que leva a pensar que, apesar das limitações, é possível minimamente criar um clima afetivo favorável, podendo ser apontado como importante forma de possibilitar diálogos para além de uma formação restrita aos conteúdos, assumindo alunos concretos e integrais, imersos em uma realidade.

Continuando nessa perspectiva, foi perguntado aos alunos se eles acreditavam que era possível a construção de uma relação afetiva no Ensino Remoto. Do total, 95,2\% alegaram ser possível e, deste número, 22,5\% fizeram ressalvas usando termos que ilustram dificuldades, como "complicado", "mais difícil", "deficiente" ou "incompleto". Um aluno ponderou sentir maior proximidade com professores com os quais já havia tido aulas anteriormente, o que corrobora com a preocupação inicial aqui retratada, acerca do desafio de construir esta relação a partir do Ensino Remoto, assim como mostra a seguinte resposta:

Acho muito mais difícil pois o professor muitas vezes não sabe nem como é o rosto de seus alunos, muitas vezes essa construção de vínculo se dá baseada nas posturas presenciais. Sendo assim, não acho que seja impossível, mas por ERE [Ensino Remoto Emergencial] isso se torna muito mais difícil (Estudante de Geografia, resposta retirada de questionário aplicado on-line, 2020).

Vale ressaltar que os próprios alunos reconhecem essa limitação do meio virtual, destacando aspectos relativos à importância da presença corporal, como reforça este outro aluno: "[...] é possível desenvolver empatia, carinho e preocupação, mas falta a conexão do olho no olho, de transferir conhecimento dentro de uma sala de poucos metros quadrados" (estudante de Geografia, resposta retirada de questionário aplicado on-line, 2020). Nesse viés, Leite (2012) destaca que certa parcela de carga afetiva que é viabilizada pelas interações entre aluno e professor concentra-se em proximidade física, posturas, tom de voz e olhares. Apesar dessas perdas em comparação com o Ensino Presencial, com base nos dados deste questionário e de relatos do diário de campo dos estagiários, pode-se perceber que as limitações do Ensino Remoto não são impeditivas para o estabelecimento de relações afetivas entre professor e aluno, dada a impossibilidade de retomar as aulas no momento atual.

Por fim, os alunos foram convidados a sugerir ações que poderiam ter sido adotadas pelos professores e promovido uma melhor relação com eles e, consequentemente, com os conteúdos 
da disciplina. Muitos alunos usaram essa pergunta aberta para tecer elogios ao esforço da professora e dos estagiários em estabelecer uma maior proximidade com a turma, em tornar as aulas mais dinâmicas: "dentro do contexto que nos encontramos, o diálogo foi além do que eu esperava” (estudante de Geografia, resposta retirada de questionário aplicado on-line, 2020). Também foi recorrente a pontuação de que as atividades avaliativas, ao todo dois trabalhos e duas provas, tornaram a disciplina mais cansativa e desgastante. Com a intenção de propor uma alternativa, uma das sugestões apresentadas foi "[...] procurar estratégias de avaliação a partir do debate, que isso na minha opinião e [sic] a única coisa que deixa leve o ensino remoto, sem isso fica difícil de aprender" (Estudante de Geografia, resposta retirada de questionário aplicado on-line, 2020).

Houve relatos que abordaram as dificuldades enfrentadas na atividade remota: "Na verdade não tenho nada a dizer de ruim sobre as aulas. Tudo muito bem feito o problema mesmo foi o meu acesso a [sic] internet e adaptação aos meios digitais. Isso piorou muito o meu rendimento." (Estudante de Geografia, resposta retirada do questionário aplicado on-line, 2020).

Creio que todos nós professores, estagiários e alunos se [sic] esforçaram em estabelecer uma boa relação e otimizar o processo de aprendizagem o quanto mais possível. Porém fatores externos de adaptação a 'nova realidade' mitigaram esses esforços de maneira que ao findar do semestre a sensação de exaustão é visível em todos (Estudante de Geografia, resposta retirada do questionário aplicado on-line, 2020).

Em outra resposta, ficou evidenciada até mesmo a decisão de trancar o curso caso esse formato emergencial de ensino continuasse por mais um período.

O contexto no qual o processo de ensino-aprendizado ocorre atravessa, inevitavelmente, a relação professor e aluno. No caso do Ensino Remoto, foram muitos os aspectos que interferiram nos desempenhos de alunos e professores, sendo que muitos sequer eram passíveis de controle:

Eu acho que por ERE [ensino remoto emergencial] não tem muito o [sic] que ser feito, é realmente ruim. Mas acho importante o diálogo com os alunos, perguntar como eles estão, se os conteúdos estão sobrecarregando ou não, o que ao [sic] meu ver foi feito desde o início [sic] dessa disciplina. Eu diria que essa foi a matéria que mais houve diálogo e flexibilidade por parte do professor (no caso professora e estagiários) não me senti intimidada ou com medo da didática utilizada (Estudante de Geografia, resposta retirada do questionário aplicado on-line, 2020).

Assim, foi possível perceber a importância dada, por vários alunos, ao cuidado dos professores com as decisões de ensino, possibilitando, de alguma forma, um enfrentamento de alguns prejuízos à aprendizagem causados pelo Ensino Remoto.

\section{CONSIDERAÇÕES FINAIS}

O trabalho buscou refletir sobre a possibilidade e os limites do estabelecimento de uma relação afetiva positiva que atravesse a tríade professor-aluno-objeto de conhecimento, no 
contexto de aulas remotas, a partir de uma experiência de estágio. Como discorrido, as decisões pedagógicas que Leite (2012) aponta, a saber: escolha dos objetivos de ensino, decisão sobre o início do processo de ensino, organização dos conteúdos, escolha dos procedimentos e atividades, e escolha dos procedimentos de avaliação, somado à criação de um clima no qual os alunos consigam participar e interagir configuram a mediação pedagógica e seus impactos afetivos na aproximação do aluno com os conteúdos de ensino como fundamentais e impreteríveis no contexto emergencial descrito aqui. Isso porque, como visto, a impossibilidade da presença física e de uma interação face a face abala essa construção de afetos, mas não a impede.

No que se refere à vivência do estágio, um importante desafio foi o fato de não ter havido contato prévio com a professora supervisora antes e isso ter se dado também pelo meio virtual o que aumentou as inseguranças quanto a esta experiência, se haveria condições para participar efetivamente do planejamento das aulas e estabelecer também uma relação com a turma a partir do lugar de estagiários. Somado a isso, como provavelmente ocorreriam no formato presencial, medos e fantasias pairavam as expectativas quanto a esse estágio, mas agora revestidos de uma roupagem nova para todos os envolvidos: um ensino remoto que se caracteriza por ser emergencial, em uma realidade marcada pelos efeitos econômicos, sociais e emocionais de uma pandemia, em que transitamos entre o lugar de alunos e de professores ao longo do semestre. Ocupar esses dois lugares com frequência colocou os licenciandos em contato com um sentimento de impotência, diante da falta de respostas e de soluções para os desafios de ambas as realidades.

Além disso, apesar de, no início, o fato da disciplina ser organizada por outra professora causar certos estranhamentos, foi extremamente formativo pensar outros textos e reelaborar atividades propostas ali, de forma que facilitasse o processo de ensino-aprendizagem. Ainda sobre o planejamento, foi muito interessante revisitar textos e conteúdos que, sob a perspectiva de estudantes, já havíamos trabalhado, mas agora com o olhar de quem, como aponta Freire (1996), irá aprender ensinando, o que envolve refletir sobre as decisões apontadas por Leite (2012), tensionando pontos relativos à forma como passar esse conteúdo considerando particularidades da turma, o cansaço do Ensino Remoto e questões fundamentais tangentes à formação de professores.

Por fim, vale frisar que este trabalho pode contribuir para a formação de outros licenciandos e professores principalmente em atividades que continuarão a ocorrer de forma remota, como parece indicar o próximo semestre. Nesse sentido, mais pesquisas sobre a afetividade são necessárias, dada a importância do aspecto afetivo no processo de ensinoaprendizagem e a necessidade de se pensar em novas estratégias e ferramentas para promover relações afetivas positivas, mesmo em ambientes virtuais.

\section{REFERÊNCIAS}

BBC NEWS BRASIL. Coronavírus: OMS declara pandemia do novo coronavírus Sars-Cov-2. 2020. Disponível em: https://www.bbc.com/portuguese/geral-51842518. Acesso em: 15 nov. 2020. 
BRASIL. Decreto $n^{\circ}$ 9.057, de 25 de maio de 2017. Regulamenta o art. 80 da lei $n^{\circ}$ 9.394, de 20 de dezembro de 1996, que estabelece as diretrizes e bases da educação nacional. Diário Oficial da União: seção 1, Brasília, DF, p. 3, 25 mai. 2017. Disponível em: http://www.planalto.gov.br/ccivil_03/_ato20152018/2017/decreto/D9057.htm. Acesso em: 05 nov. 2020.

BRASIL. Ministério da Educação. Portaria n 544, de 16 de junho de 2020. Dispõe sobre a substituição das aulas presenciais por aulas em meios digitais, enquanto durar a situação de pandemia do novo conoravírus - Covid-19, e revoga as Portarias MEC $n^{\circ} 343$, de 17 de março de 2020, $n^{\circ} 345$, de 19 de março de 2020, e $n^{\circ}$ 473, de 12 de maio de 2020. Diário Oficial da União: seção 1, Brasília, DF, n. 114, p. 62, 17 jun. 2020a. Disponível em: http://www.in.gov.br/web/dou/-/portaria-n-544-de-16-de-junho-de-2020261924872. Acesso em: 28 mar. 2021.

BRASIL. Ministério da Educação. Portaria ${ }^{\circ}$ 343, de 17 de março de 2020. Dispõe sobre a substituição das aulas presenciais por aulas em meios digitais enquanto durar a situação da pandemia do Novo Coronavírus-COVID-19. Diário Oficial da União: seção 1, Brasília, DF, p. 39, 18 mar. 2020b. Disponível em: http://www.planalto.gov.br/CCIVIL_03/Portaria/PRT/Portaria\%20n\%C2\%BA\%20343-20-mec.htm. Acesso em: 15 nov. 2020.

CRESWELL, J. W. Procedimentos de métodos mistos. In: CRESWELL, J. W. Projeto de Pesquisa: Métodos qualitativo, quantitativo e misto. 2. ed. Porto Alegre: Artmed, 2007.

FREIRE, P. Pedagogia da Autonomia: saberes necessários à prática educativa. São Paulo: Paz e Terra, 1996.

GALVÃO, I. Expressividade e emoções segundo a perspectiva de Wallon. In: ARANTES, V. A. (Org.).

Afetividade na escola: alternativas teóricas e práticas. São Paulo: Summus, 2003.

GOIÁS. Secretaria de Estado da Saúde. Nota Técnica SES - GO n: 1/2020 - GAB- 03076, de 15 março de 2020. Dispõe da Paralisação das Aulas em todos os níveis educacionais, públicos e privados, por 15 dias, podendo ser prorrogável. Goiás: SES/GO, 2020. Disponível em:

https://www.saude.go.gov.br/files/banner_coronavirus/notatecnica.pdf. Acesso em: 15 nov. 2020.

JOYE, C. R.; MOREIRA, M. M.; ROCHA, S. S. D. Educação a Distância ou Atividade Educacional Remota Emergencial: em busca do elo perdido da educação escolar em tempos de COVID-19. Research, Society and Development, Vargem Grande Paulista, v. 9, n. 7, p. e521974299, mai. 2020. Disponível em: https://rsdjournal.org/index.php/rsd/article/view/4299. Acesso em: 08 nov. 2020.

LEITE, S. A. S. Afetividade nas práticas pedagógicas. Temas em psicologia, Ribeirão Preto, v. 20, n. 2, p. 355-368, dez. 2012. Disponível em: https://www.redalyc.org/articulo.oa?id=513751440006. Acesso em: 04 nov. 2020.

LIMA, M. S. L.; PIMENTA, S. G. Estágio e docência: diferentes concepções. Poíesis Pedagógica, Catalão, v. 3, n. 3-4, p. 5-24, out. 2006. Disponível em: https://www.revistas.ufg.br/poiesis/article/view/10542. Acesso em: 05 nov. 2020.

MAHONEY, A. A. A constituição da pessoa: desenvolvimento e aprendizagem. In: MAHONEY, A. A.; ALMEIDA, L. R. (Org.). A constituição da pessoa na proposta de Henri Wallon. São Paulo: Edições Loyola, 2004.

MAHONEY, A. A.; ALMEIDA, L. R. Afetividade e processo ensino-aprendizagem: contribuições de Henri Wallon. Psicologia da Educação, São Paulo, n. 20, p. 11-30, 2005. Disponível em:

https://revistas.pucsp.br/index.php/psicoeduca/article/view/43324. Acesso em: 15 nov. 2020.

PRÓ-REITORIA DE GRADUAÇÃO (PROGRAD). Geografia: Licenciatura: Goiânia. 2020. Disponível em: https://prograd.ufg.br/p/8959-geografia-licenciatura-goiania. Acesso em: 22 nov. 2020. 
SÁ, A. C. A. M. et al. (Org.). Diretrizes didático-pedagógicas para a organização do ensino remoto na UFG. Goiânia: CEGRAF UFG, 2020. Ebook. Disponível em: https://publica.ciar.ufg.br/ebooks/ensinoremoto- UFG /index.html. Acesso em: 10 nov. 2020.

SANTOS, J. L. G. et al. Integração entre dados quantitativos e qualitativos em uma pesquisa de métodos mistos. Texto \& contexto: enfermagem, Florianópolis, v. 26, n. 3, e1590016, 2017. Disponível em: http://www.scielo.br/scielo.php?script=sci_arttext\&pid=S0104-07072017000300330\&lng=en\&nrm=iso. Acesso em: 30 mar. 2021.

TASSONI, E. C. M. Afetividade e aprendizagem: a relação professor-aluno. Psicologia, análise e crítica da prática educacional. Campinas: ANPED, 2000.

UNIVERSIDADE FEDERAL DE GOIÁS (UFG). RESOLUÇÃO - CEPEC N 1541. Estabelece a política para a formação de professores(as) da educação básica, da Universidade Federal de Goiás (UFG), e dá outras providências, revogando-se a Resolução CEPEC n 631/2003. Goiás: UFG, 2017. Disponível em: https://sistemas.ufg.br/consultas_publicas/resolucoes/arquivos/Resolucao_CEPEC_2017_1541.pdf. Acesso em: 30 mar 2020.

UNIVERSIDADE FEDERAL DE GOIÁS (UFG). Portaria SEI n $\mathbf{1 0}$, de 10 de junho de 2020. Dispõe sobre o Plano Emergencial de Conectividade para estudantes da UFG. Goiás: UFG, 2020a. Disponível em: https://files.cercomp.UFG.br/weby/up/93/o/SEI_UFG_-_1378882_-_PORTARIA_PEC_SEI.pdf?1592344091. Acesso em: 30 mar 2020.

UNIVERSIDADE FEDERAL DE GOIÁS (UFG). Projeto Pedagógico do Curso de Licenciatura em Geografia. Goiás: UFG, 2015. Disponível em: https://files.cercomp.ufg.br/weby/up/51/o/PPC_Geografia_2015__Licenciatura_IESA_UFG_-_atualizado_07maio2019.pdf. Acesso em: 30 mar. 2020.

UNIVERSIDADE FEDERAL DE GOIÁS (UFG). Resolução CONSUNI N 0027/2020, de 06 de julho de 2020. Regulamenta o empréstimo emergencial de equipamentos de informática aos discentes de educação básica, graduação e pós-graduação stricto sensu, durante o período excepcional de isolamento social, enquanto durar a situação de pandemia do novo coronavírus - Covid-19. Goiás: UFG, 2020b. Disponível em: https://files.cercomp.ufg.br/weby/up/93/o/Resolucao_CONSUNI_2020_0027-SEI.pdf?1594155300. Acesso em: 30 mar. 2020.

VIÉGAS, L. S. Reflexões sobre a pesquisa etnográfica em Psicologia e Educação. Diálogos possíveis, Salvador, v. 1, n. 9, p. 101-123, jan./jun. 2007. Disponível em: https://tuxdoc.com/download/reflexoessobre-a-pesquisa-etnografica-em-psicologia-e-educaao_pdf. Acesso em: 22 nov. 2020.

VIGOTSKI, L. S. A formação social da mente. 6. ed. São Paulo: Martins Fontes, 1998.

WALLON, H. A evolução psicológica da criança. São Paulo: Martins Fontes, 2007. 